\title{
Classical biological control: exploiting enemy escape to manage plant invasions
}

\author{
Heinz Müller-Schärer · Urs Schaffner
}

Published online: 15 March 2008

(C) Springer Science+Business Media B.V. 2008

\begin{abstract}
Practitioners of classical biological control of invasive weeds are confronted with a dual expectation: to achieve successful control of plant invaders and to avoid damage to nontarget plants and adverse indirect effects. In this paper we discuss key issues that we consider to be crucial for a safe, efficient, and successful classical biological control project, and that have also caused some recent controversy. These include selection of effective control agents, host specificity of the biological control agents, implications of the genetic population structure of the target populations, and potential impact on native food webs. With regard to improving the success rate of biological control of plant invaders, we first emphasize the importance of a clear a priori definition of success and a more ecosystembased approach to better document both negative effects of the invasive plant as well as potential positive and negative effects of introducing biological control agents. Secondly, pre-release impact assessment could be improved by better focusing on
\end{abstract}

H. Müller-Schärer $(\bowtie)$

Département de Biologie/Ecologie \& Evolution, Université de Fribourg/Pérolles, Chemin du Musée 10, 1700 Fribourg, Switzerland

e-mail: heinz.mueller@unifr.ch

U. Schaffner

CABI Europe-Switzerland, Rue des Grillons 1, 2800 Delemont, Switzerland

e-mail: u.schaffner@cabi.org how to reach high densities of the control agents and by including tolerance to and compensation of herbivory. Thirdly, we advocate a reinforced effort to integrate and combine biological control in combination with existing or potential management options. Finally, we propose various ecological and evolutionary hypotheses in the framework of our topic to document that biological control programmes against plant invaders also offer a great opportunity to gain new insights into basic processes in ecology and evolution.

Keywords Biological control .

Ecological and evolutionary processes . Impact assessment · Nontarget effects .

Plant invasions

\section{Introduction}

Classical biological control of exotic weeds aims to mitigate the negative impact of invasive weeds on biodiversity, human welfare, and economy. It implies the deliberate release of specialist natural enemies from the weed's native range to reduce the abundance of a weed in its introduced range below an ecological or economic threshold. Classical biological control can be a highly effective and cost-efficient approach to control invasive weeds. Myers and Bazely (2003) listed some 40 invasive weed species that are considered to be under control at least at a regional 
level due to the release of biological control agents. In a recent economic assessment of 29 Australian weed biological control programmes, the annual benefit was estimated at 95.3 million Australian dollars and the annual investment at 4.3 million Australian dollars-a benefit to cost ratio of 23:1 (Page and Lacey 2006).

The framework of a classical biological control project generally consists of six stages: target weed ecology, exploration for potential control agents, evaluation of biological control potential, host-specificity testing, agent release and redistribution, and agent evaluation (Briese 2000; van Klinken and Raghu 2006) (Fig. 1). A large body of literature has accumulated over the past 150 year history of biological weed control on each of these topics and excellent reviews have reported the developments reached so far in making biological control a more predictive science (see, e.g., Sheppard et al. 2005; van Klinken and Raghu 2006, with regard to hostspecificity testing and agent selection, respectively).

Modern practice of classical biological control of invasive plants offers an ideal study system to test and further advance basic ecological and evolutionary theory (cf. below). This old and widely applied approach is based on the fact that herbivores and pathogens have the ability to suppress the population densities of their host plants, that at least some of them have a narrow host range, and that exotic plant invaders are generally introduced into a new range without their specific natural enemies (McFadyen
1998; Briese 2000, 2004). The observation that invasive exotic plants do indeed suffer a reduced overall amount of herbivore damage (Wolfe 2002; Cappuccino and Carpenter 2005), or are attacked by fewer herbivorous invertebrates (Keane and Crawley 2002) and fungal and viral pathogens (Mitchell and Power 2003), as compared with the same species in their native range also formed the basis of one of the most prominent explanations for biological invasions, the enemy release hypothesis (ERH, Elton 1958). The ERH assumes that plant species, on introduction into a new range, experience a reduction in top-down regulation by natural enemies, which allows them to outcompete the native plants in the introduced range and to increase in abundance. Hence, the ERH comprises a bio-geographic comparison (reduced top-down regulation in the introduced versus native range) and a community-based comparison (natural enemies native to the invaded range have a higher impact on native than on invasive species). It has been claimed that successful biological control is strong evidence for the ERH, i.e., that those invasive plants that were brought under control after the release of specialist natural enemies had originally become invasive due to the release from specialist natural enemies (DeLoach 1995). However, besides escape from specialist antagonists, a variety of abiotic (e.g., climate, nutrient conditions, fire frequency) or biotic (e.g., mutualists, soil microbes, competition with plants) factors differ between the native and the introduced range and may have contributed to the
Fig. 1 Stages in a modern biological control programme (indicated by boxes arranged in the centre from top to bottom) (adapted from Briese 2000; van Klinken and Raghu 2006), and issues addressed in this manuscript (in shaded boxes) with their connections to the programme stages

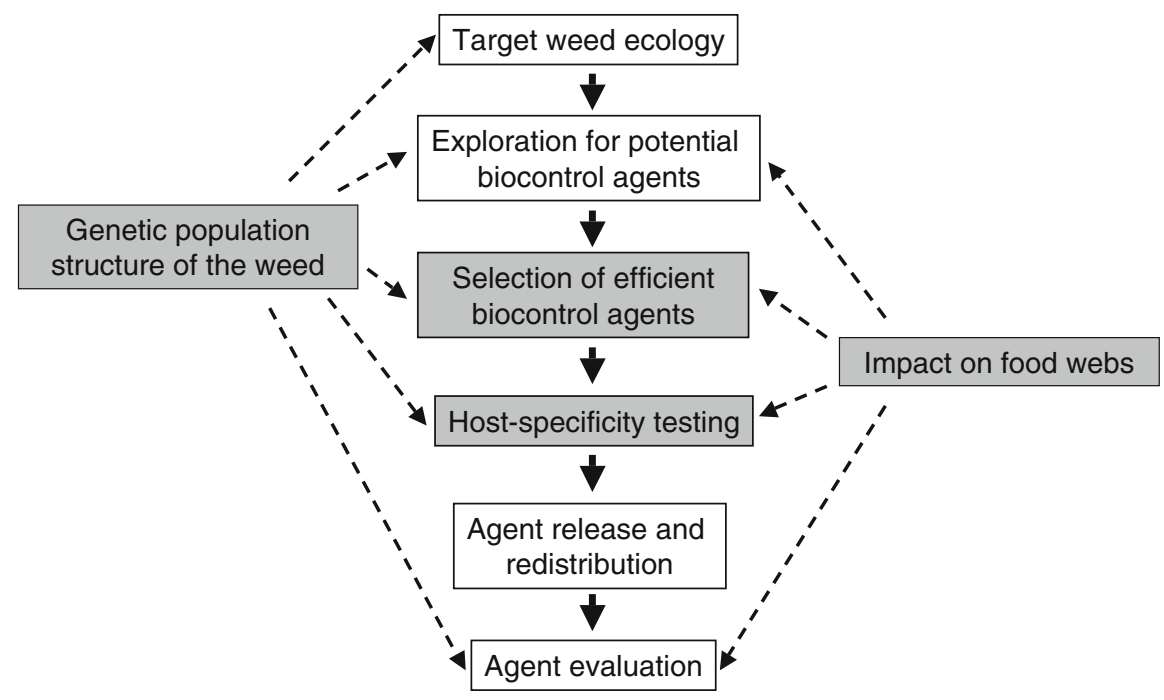


invasion success of some of the introduced plant species (Myers and Bazely 2003). Moreover, species may just possess traits that make them pre-adapted for invasion. Hence, the fact that a specialist herbivore can reduce the population density of a weed in the introduced range does not necessarily mean that the release from this specialist has caused the invasion (Keane and Crawley 2002); for example, the chrysomelid beetle Aphthona lacertosa, a biological control agent against leafy spurge (Euphorbia esula), can reach densities of hundreds of adults per $\mathrm{m}^{2}$ in the introduced range (Kalischuk et al. 2004). The same species is usually found only at densities two and more orders of magnitude lower in the native range, making a top-down regulation of leafy spurge by this specialist in the native range unlikely. Thus, classical biological control does not aim to restore herbivore pressure to a level found in the native range; the goal is to alter the community-based imbalance in herbivore pressure in the introduced range through partially restoring the bio-geographic imbalance in the herbivore species assemblage caused by the introduction. Hence, classical biological control may be a suitable strategy to control invasive plants even when the mechanism underlying the invasion is not the release from specialist herbivory. Furthermore, even if the plant populations are limited by the biocontrol agents both in the native and introduced range, the mechanisms might well be different.

The introduction of classical biological control agents into a new range entails some level of uncertainty in terms of potential direct or indirect negative effects on native species or ecosystem processes. Hence, practitioners of classical biological control are confronted with a dual expectation: to achieve successful control of plant invaders and to avoid damage to nontarget plants and adverse indirect effects. In this paper we will first briefly describe the different methods and strategies of weed biocontrol. We will then concentrate on classical biological control to mitigate the negative effects of invasive plants, and discuss a few key issues that we consider crucial for a safe, efficient and successful biocontrol project, and that have also caused some recent controversy (Louda et al. 2003; Pearson and Callaway 2003; Thomas and Reid 2007): (i) selection of efficient control agents, (ii) host specificity of the biological control agents, (iii) implications of the genetic population structure of the target populations, and (iv) potential impact on native food webs (Fig. 1). We then propose future studies in the field of plant invasions and biological control that may not only lead to a more targeted and predictive biocontrol management, but also offer new insights into basic ecology and evolution and thus advance both disciplines.

The following is not intended as a review of the many complex stages involved in a weed biological control project. We would rather like to inform researchers and practitioners who are involved in managing plant invasions and are interested in biological control about some critical issues when applying this potentially powerful management option. Our overview might also be of interest to students and researchers interested in linking ecological and evolutionary theory with practical applications.

\section{Methods and strategies of weed biocontrol}

Three principal methods of biological weed control can be distinguished based on the three factors: target habitat, origin of the control agent, and the amount of initial inoculum used (Müller-Schärer 2002, Fig. 2). (i) The inoculative (or classical) approach aims to control naturalized weeds by the introduction of exotic control organisms from the weed's native range. They are released over only a small area of the total weed infestation and control is achieved gradually. Successful control depends on favorable conditions promoting an increase, spread and impact of the control agent's population, thereby causing a reduction of the target weed population. (ii) The inundative or bioherbicide method uses periodic releases of an abundant supply of a native or exotic control agent over the entire weed population to be controlled. Such biological agents generally are manufactured, formulated, standardized, packaged, and registered like chemical herbicides. Compared to the other two approaches, this approach is characterized by higher application costs and a relatively short time period to achieve a potential control success, mainly by reducing the biomass of the target weed. (iii) More recently, the system management approach of biological weed control had been described (Müller-Schärer and Frantzen 1996; Müller-Schärer and Rieger 1998; Grace and Müller-Schärer 2002). It is related to the conservation and augmentative 


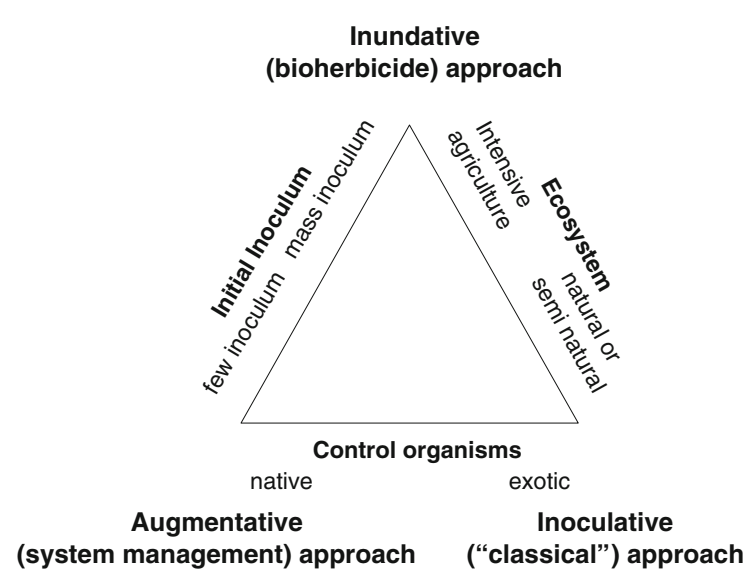

Fig. 2 Methods of biological weed control and their application

approaches distinguished by some authors (McFadyen 1998). Its aim is to shift the competitive weedcrop relationship in favor of the latter, mainly by stimulating the build up of a disease epidemic or insect outbreak on the target weed population. The approach excludes the use of exotic organisms (classical approach) and the use of mass amounts of inoculum applied like a herbicide to the whole weed population (bioherbicide approach).

While both the inundative and the augmentative or system management approach are primarily aimed at crop weeds, the classical approach has traditionally and most successfully been used against plant invaders (also called environmental weeds) spreading over large areas of natural and seminatural habitats, extensively managed agro-ecosystems or aquatic ecosystems (Müller-Schärer et al. 2000). In the following, we will thus focus on this latter approach and mainly consider the predominantly used insect herbivores as biological control agents.

\section{Selected key issues of classical biological control against plant invaders}

Selection of effective biological control agents

It is well known, especially from the vast literature on crop pests, that natural enemies affect plant performance, such as by reducing biomass or seed production, or altering flowering phenology. As stated by Crawley (1989), it is, however, an entirely different matter to demonstrate that natural enemies affect plant population dynamics. Population regulation in the wild is still largely unknown and the few case studies indicate complex interactions among multiple factors, both abiotic and biotic (Silvertown and Charlesworth 2001).

Host-specificity testing (cf. below) is the nonnegotiable and generally the most time-consuming and expensive part of a biological control project. The result is that practitioners are pressured to test only potentially effective agents. The selection of the most efficient agents from the many species encountered and studied during field surveys in the area of origin and, more precisely, the prediction of their efficacy in a new environment, clearly presents a great scientific challenge. The strategy referred to as the lottery model describes the introduction of a number of agents to increase the probability of including an effective agent (Myers 1985). This is in contrast to the cumulative stress model (Harris 1985) that considers success to arise from different types of attack associated with different species. Both of these approaches assume that the scientifically based prioritization is too complex and therefore suggest to put the resources into host-range testing and release of large numbers of agents to maximize the chance of control success. Presently, they are no longer debated due to the increasing safety concerns involved when introducing exotic species (Simberloff and Stiling 1996).

A range of approaches to agent selection has been adopted over time, starting from rules of thumb, such as giving priority to agents abundant in areas of the native range that are ecoclimatically similar to the target range or selecting competitively superior species (see van Klinken and Raghu 2006). The use of scoring systems (e.g., Harris 1973; Goeden 1983) was the first attempt to make agent selection more rigorous (see also McClay and Balciunas 2005, for a more recent version of such scoring systems). However, they mainly focus on attributes of the agents and their ability to damage a plant (fecundity, number of generations per year, activity period, etc.), largely ignoring characteristics of the target weed and population-level effects. An experimental and phytocentric approach for agent selection has been put forward only some 20 years ago (see, e.g., Müller 1988) and has now become an integral part of a biological control project. Studies that compare the weed's population dynamics in its native and 
introduced ranges may indicate both causes of invasiveness as well as the lifecycle transition most susceptible to population change, which should therefore be targeted by biocontrol agents (Sheppard 2003). For example, biological control agents may be able to reduce the individual growth rate or cause mortality of young plants, but need not necessarily cause changes in the population density. Similarly, seed feeders may greatly impair seed output without reducing the density of non-seed-limited populations (Maron and Gardner 2000). Studying the plant response to simulated or actual herbivory may further help identifying the type, amount, and timing of damage required to reduce the weed's population density below an economic or ecological threshold (Raghu et al. 2006).

Studies of the weed's population dynamics when prioritizing potential biological control agents have also made important contributions towards a better understanding of plant-herbivore interactions. These include clarifications such as the relative importance of above- versus below-ground herbivory in affecting plants differing in lifecycle (annuals versus biennials and perennials), the type of agents most likely to affect particular life-history stages of their host plant, and the role of intra- and interspecific plant competition (e.g., Müller 1991; Sheppard et al. 1994). Despite the long history of predator-prey models based on Lotka-Volterra models and the use of discrete-time models in host-parasitoid interactions both in general ecology and in arthropod biological control, there are only a few studies of coupled plantinsect herbivore systems in the general ecological literature (Silvertown and Charlesworth 2001; Buckley et al. 2005). Weed-herbivore models used in biological control up until 10 years ago concentrated solely on the plant dynamics, ignoring herbivore dynamics (Buckley et al. 2005). Recent progress has been made by developing coupled plant-herbivore models that allow feedback from plant to herbivore populations and vice versa. Based on both experimental and field data, such models have now been extended to include a seed bank, density-dependent plant fecundity, competition between the control organisms, plant tolerance to herbivory, and densityrelated interactions (Buckley et al. 2005). These studies constitute a great progress towards identifying those characteristics of plant and biocontrol agent populations that not only provide environmentally or economically acceptable control, but which also lead to control that is stable and sustainable, thus facilitating a better choice of efficient control organisms.

In this context, it is important to remember that explicitly defining success is crucial not only for agent selection, but also for deciding whether biological control is an appropriate management option. Success may range from reducing the biomass of plant individuals to altering community patterns, such as relative species composition, or processes, such as restoring desirable levels of hydrological flow threatened by aquatic weeds (van Klinken and Raghu 2006). For example, seed feeders have little impact on established plants, but they might be a major component of a management scheme aiming at reducing the spread of a weed into sensitive areas. This has been followed in the biological control project against exotic Acacia species in South Africa that were originally introduced and are still used for commercial purposes but have started invading the fynbos (Dennill and Donnelly 1991). The conflict of interest has been resolved by introducing only seed-feeding insects that are now claimed to have stopped further spread of several Acacia species without affecting commercial activities or their role as shade trees for grazing cattle (Hoffmann et al. 2002; Impson et al. 2004).

Host specificity of the biological control agents

Analyzing risks to predict the likelihood of nontarget effects by a potential biological control agent after its introduction into the invaded range is one of the fundamental challenges of pre-release studies. Various reviews have dealt with the methodology to assess the fundamental (the list of plant species on which a herbivore can complete its full lifecycle or specific stages during its lifecycle) and ecological host range (the subset of plant species from the fundamental host range that are actually used under field conditions) (e.g., Withers et al. 1999; van Klinken 2000; Schaffner 2001; Sheppard et al. 2005). Here we would like to address three critical aspects in terms of pre-release host-specificity testing in weed biological control projects: (1) the selection of test plant species which should allow extrapolation of the test results to all plants native to the area of introduction, (2) a scientifically based assessment of which plants within the fundamental host range will experience significant damage under open-field 
conditions in the new range, including the assessment of intrinsic and extrinsic factors affecting host fidelity by a biological control candidate, and (3) the assessment of the likelihood of evolutionary changes in their preference or performance.

Ehrlich and Raven (1964) were among the first suggesting that the host ranges of herbivorous insects are usually restricted to a set of phylogenetically related plant species, and that the host plants also tended to share similar secondary chemistry. This suggested pattern prompted Harris and Zwölfer (1968) and Wapshere (1974) to propose the centrifugalphylogenetic method for selecting test plant species. It involves selecting and testing plants of increasingly distant phylogenetic relationship to the target weed. As a safeguard against disjunct host ranges, i.e., host ranges that include plant species from only distantly related taxa, it has been proposed to add plants that are economically important, have similar phytochemical or morphological characteristics, or that are attacked by herbivores closely related to the biological control candidate (Harris and Zwölfer 1968).

To date, experimental and comparative studies have accumulated strong evidence that host associations are indeed very often conserved at higher plant taxonomic levels, such as tribes or families (Bernays 2000; Futuyma 2000). Briese (2003) therefore suggested to drop the categories of safeguard species when composing the test plant list, since testing these species provides no additional information but may slow down the screening process. On the other hand, there is still surprisingly little information available on the conservatism of host use of specialist herbivores at lower taxonomic levels, e.g., among congeneric species. This may cause concern in those cases where the target weed belongs to a species-rich genus and when at least some species of that genus are native to the area of introduction. As pointed out by Pemberton (2000), virtually all native plant species attacked by biological control agents are closely related to the target weed. Examples of invasive plants that have been or are targets of biological control and that belong to species-rich genera are tansy ragwort, Jacobaea vulgaris (or Senecio jacobaea), sulfur cinquefoil, Potentilla recta, and Canada thistle, Cirsium arvense. Recently published phylogenies on speciose plant genera, such as that on the Senecio complex (Pelser et al. 2002), offer the opportunity to test whether the host range of specialist herbivores that are not strictly monophagous can also be circumscribed by well-defined clades within the phylogenetic tree of a genus or a complex of closely related genera. The measurement of risk to nontarget species may be further refined by limiting host-specificity tests to those closely related nontarget species that show bio-geographical overlap or ecological similarity (e.g., similar life-history, Briese 2003; Briese 2005).

The fundamental host range of a biological control candidate is often relatively easily described, but predicting which nontarget species within the fundamental host range will be utilized in the field, and the relative level of attack, is more difficult as it depends on a wide range of intrinsic and extrinsic factors (e.g., van Klinken 2000; Sheppard et al. 2005). Unless a candidate biological control agent is strictly monophagous under no-choice conditions, the results of prerelease host-range studies may therefore depend on the experimental test adopted (Blossey 1995). Interpretation of such results is particularly troublesome when they do not match with the ecological host range of the biological control candidate in its native range. Possible intrinsic and extrinsic factors underlying such apparently contradicting results include age, experience or egg load of females, time since the females had encountered a preferred host, experimental conditions that cause the females to bypass cues relevant to the early stages of host finding, temperature or air pressure (see reviews by Withers and Barton Brown 1998; Roitberg 2000). While a full assessment of the various factors affecting hostselection behavior is probably not feasible, we argue that the results of host-range studies become more easily interpretable when more types of experiments are used in pre-release studies. Theoretical frameworks on host-selection behavior can facilitate the interpretation of apparently conflicting results from different experiments and/or from field observations. For example, the hierarchical threshold model proposed by Courtney et al. (1989) predicts that, although the degree of acceptability of the host plants may change depending on the intrinsic and extrinsic factors a gravid female experiences, their ranking will not be influenced. Turanli and Schaffner (2004) investigated the oviposition specificity of the sesiid moth Tinthia myrmosaeformis under varying levels of behavioural restrictions and concluded that the results are largely in agreement with Courtney 
et al.'s (1989) model, and that the different levels of host specificity exhibited can be explained by different motivational thresholds experienced by the females under the different test designs.

The fact that a living biological control agent is introduced into a new environment in which it will encounter a new set of selection pressures raises the concern of post-introduction host shifts, i.e., genetic changes in preference or performance (Schaffner 2001). In fact, some of the best examples of rapid evolution stem from studies on food webs associated with introduced species (Lee 2002). However, in those cases where host shifts have been shown to occur in a relatively short period of time, some initial level of acceptance of the derived host was already present at the beginning of the investigations (Thompson 1998; Schaffner 2001; van Klinken and Edwards 2002). Hence, more detailed studies on the likelihood of host shifts in biological control agents, e.g., by carrying out quantitative genetic studies (e.g., Karowe 1990) or selection experiments (e.g., Fry 1990; Agrawal 2000), may focus on those plant species that are within the fundamental host range but are currently lower ranked than the target weed. Several biological control candidates may not be suitable for testing in such a sophisticated experimental set-up. However, current evidence suggests that the risk of rapid host shifts in biological control agents is small (van Klinken and Edwards 2002) and, in fact, it has never been documented. It is beyond the scope of pre-release studies to experimentally assess the likelihood of long-term evolution in preference or performance of biocontrol agents. A comparative approach assessing the phylogeny of host association in the insect clade to which the biocontrol agents belongs may help to make predictions on such longterm processes (Briese 1996).

In conclusion, the interpretation of host-specificity studies and the prediction of the ecological host range of a biological control agent after its introduction into a new range entail some level of uncertainties. The long history of pre-release studies in weed biological control has significantly contributed to the development of environmental risk assessment procedures, from which other approaches such as classical biological control against arthropod pests can also profit. In some countries, regulations have been put in place that allow simultaneous consideration of both potential risks and benefits of classical biological control and other management options, including doing nothing, in the decision process (Sheppard et al. 2003). It would be highly desirable if more national regulations would adopt such an approach.

Genetic structure of the target population and implications for biological control

Above, we have discussed the importance of detailed monitoring of changes in numbers of individuals over time for understanding the interrelated population dynamics of the weed and its antagonists as a prerequisite for agent selection and thus biocontrol success. When birth, death, immigration, and emigration rates affect genotypes differently, they may produce evolutionary change in frequencies of alleles and genetic loci. Cross-continental comparisons based on experiments under homogeneous environmental conditions suggest that plant invasions often involve rapid evolutionary change (Bossdorf et al. 2005). Founder effects, hybridization, and adaptation to novel environments cause genetic differentiation between native and introduced populations and may not only contribute to the success of invaders, but will also affect subsequent biological control management (Müller-Schärer et al. 2004; Müller-Schärer and Steinger 2004). Formally, the rate of adaptive evolution is determined by two components: heritable genetic variation and selection (Falconer and Mackay 1996). The evolutionary response is expected to increase with increasing genetic variation and with increasing selection intensity, i.e., the difference between the current and the optimal trait values in the new range. The amount of genetic variation harboured within invasive populations and on which selection can act is thus a crucial determinant of the potential of a population to adapt to novel environments (Table 1).

Because the process of invasion frequently involves genetic bottlenecks followed by inbreeding, populations in the exotic range were usually thought to be genetically depauperate as compared with populations from the native range (Barrett and Husband 1990). This has indeed been confirmed by several genetic marker studies (e.g., Neuffer and Hurka 1999). For example, in the case of Rubus alceifolius, invading populations on three Indian Ocean islands comprised only a single genotype reproducing by apomixis, i.e., asexual production of seeds (Amsellem et al. 2000, Table 1a). Low levels of genetic variation may 
Table 1 Processes determining genetic diversity in the new range and expected consequences for plant invasion and subsequent biological control

\begin{tabular}{lcc}
\hline Processes & Consequences for plant invasion & Consequences for biocontrol \\
\hline $\begin{array}{l}\text { (a) Reducing genetic variation } \\
\begin{array}{c}\text { Founder effects, genetic drift, inbreeding } \\
\text { and inbreeding depression (e.g., Rubus } \\
\text { alceifolius, Amsellem et al. 2000) }\end{array}\end{array}$ & $\begin{array}{c}\text { Low genetic variation, low adaptive } \\
\text { potential, low population fitness }\end{array}$ & $\begin{array}{c}\text { High biocontrol efficacy when highly } \\
\text { adapted agents are released, high chance } \\
\text { of rapid spread (Burdon and Marshall } \\
1981)\end{array}$
\end{tabular}

\section{(b) Increasing genetic variation}

Mixing of previously isolated populations (possibly with significant genetic variation between populations in the native range) (e.g., Heracleum mantegazzianum, Walker et al. 2003)

Interspecific hybridization and polyploidization

(i) Introduced $\times$ native (e.g., Spartina anglica, Ayres and Strong 2001)

(ii) Introduced $\times$ introduced (e.g., Tamarix, Gaskin and Schaal 2002)

\author{
New genotype assemblages created after \\ recombination, potential for rapid \\ adaptive evolution
}

New genotypes created with novel trait combinations or transgressive phenotypes providing raw material for rapid evolution, fixed heterosis boosts fitness
Biocontrol efficacy may be low when agents encounter new (combinations of) plant defence traits (Burdon and Marshall 1981)

Biocontrol agents may fail to accept hybrid host or have low performance. However, empirical evidence also suggests reduced insect and pathogen resistance in hybrids (Fritz et al. 1999) influence plant-antagonist dynamics both in the short and long term. Data from several agricultural studies comparing disease dynamics in crop monocultures and in multiline mixtures have demonstrated that low levels of genetic variation can accelerate the development of epidemics within the field (Finckh and Wolfe 1997; Garrett and Mundt 1999; Zhu et al. 2000). Similarly, in their review on biological control and the reproductive mode of weeds, Burdon and Marshall (1981) found that apomictic and other asexually reproducing plants were effectively controlled more often than sexually reproducing plants (but see Chaboudez and Sheppard 1995). Thus, genetic uniformity in introduced plant populations is expected to increase biocontrol efficacy (Table 1a). However, low levels of genetic variation (and therefore a limited potential to adapt) seem not to be a general feature of invasive plant populations (e.g., Novak and Mack 1993; Schierenbeck et al. 1995; Bossdorf et al. 2005). This could be due to several processes (Table 1b). First, it is increasingly being recognized that low within-population diversity in neutral genetic markers does not necessarily reflect low additive genetic variation in quantitative traits relevant for adaptive evolution (Reed and Frankham 2001). Second, there is increasing evidence from molecular marker studies showing that multiple introductions of propagules into the exotic range are rather common (Neuffer and Hurka 1999). If source populations in the native range are genetically highly structured, such multiple introductions can contribute to increased within-population diversity in the exotic range. Third, interspecific hybridization between introduced taxa and either native or other introduced taxa seems to precede several contemporary invasions (reviewed in Ellstrand and Schierenbeck 2000). Gaskin and Schaal (2002) recently showed that dominant invasive populations of Tamarix in the USA might originate from a cross between two Eurasian species, which rarely hybridize in their native range even where they co-occur. An important question with regard to biological control is how plant hybridization affects resistance and tolerance to herbivores and pathogens (Table $1 \mathrm{~b}$, cf. also Table 2d). This subject is understudied but available evidence suggests that hybrids often have lower resistance than their parents. In their review, Fritz et al. (1999) reported that, in cases in which parental taxa differed in resistance, hybrids were in a majority of cases $(56 \%)$ equally or more susceptible than the susceptible parent, whereas intermediate levels of resistance and resemblance to the resistant parent were less common ( $29 \%$ and $15 \%$ of cases, respectively). Of course, the importance of genetic variation and its change over time for biocontrol depends on the agents under consideration, as some were found to clearly differentiate among genotypes for both preference and performance, while others do not (Goolsby et al. 2006). 
Little is yet known about potential shifts in plant trait means that are relevant for herbivory under novel selection in the new range (Müller-Schärer and Steinger 2004). An influential idea in this context has been the evolution of increased competitive ability (EICA) Hypothesis (Blossey and Nötzold 1995). It states that plants introduced into new areas may evolve reduced allocation to costly defence, allowing them to increase allocation to growth and/or reproduction in the absence of enemies. Some studies examining EICA have found a loss of defence in plants from introduced populations but only a few have demonstrated altered resource allocation patterns that may favor growth and reproduction and ultimately facilitate demographic expansion of populations in the introduced range (Bossdorf et al. 2005; Handley et al. 2008, and references therein). Recently, MüllerSchärer et al. (2004) explored potential evolutionary trajectories of plant traits associated with herbivore defence in the new range and presented hypotheses about how these might influence the efficacy of biological control (cf. Table 2).

Predicting consequences of evolutionary change in invasive plants for plant-herbivore interactions would involve unravelling the innumerable processes from changes in gene frequencies to plant fitness, population dynamics, and community interactions. This opens up a wide range of future studies that not only address important processes at various levels of plantherbivore interactions, but will hopefully also make the outcome of biological control more predictable.

\section{Potential impact on native food webs}

Traditionally, it has been assumed that the only risk associated with the introduction of weed biological control agents were damage to native nontarget plant species. However, recent studies indicate that even specialist biological control agents can exhibit negative indirect effects on other species native to the introduced range (Cory and Myers 2000). Pearson and Callaway (2003) proposed that the greatest likelihood for negative indirect effects is when the biological control agent builds up high densities but has no or only minimal impact on the population dynamics of the target weed. For example, two gall flies introduced as biological control agents against invasive knapweeds (Centaurea maculosa and $C$. diffusa) have built up high population densities but have failed to control the population densities of their host plants (cf. below and Table 2c). These abundant flies have become an integral part of the winter diet of a generalist predator, the deer mouse Peromyscus maniculatus, and has elevated the deer mouse population two- to threefold in knapweed-invaded grasslands. Such an increase of a generalist predator is likely to disrupt established food

Table 2 Evolutionary hypotheses related to plant invasions and biological control efficacy and success (adapted from MüllerSchärer et al. 2004)

Hypotheses Explanations

(a) Biological control will be most efficient when invasive populations are genetically depauperate.

(b) Plants that have evolved increased vigor in the exotic range will experience a particularly fast population build-up of biocontrol agents.

(c) The impact of biocontrol herbivores on plant performance will depend on the type of plant defence evolved during the invasion process in the absence of specialist herbivores.

(d) Hybrids are more susceptible to herbivores because they inherit defence chemicals from both parents in too low concentrations to be effective.

(e) Increased genetic variation through population mixing of the biological control agent (with each population tested for host specificity) prior to release will increase both population build-up and agent impact.
Population build-up of highly adapted biocontrol agents will be fast. Even low genetic diversity might, however, reduce biocontrol sustainability in the long term.

This is based on the assumption that increased vigor has evolved at the expense of quantitative defence and that increased levels of toxins in response to selection by generalist herbivores might benefit host finding by adapted specialist biocontrol agents.

If trade-offs exist between tolerance and resistance, we might expect higher per capita and overall impact of biocontrol agents on plant genotypes that are chemically defended by toxins and lower impact on the tolerant genotypes.

Biocontrol agents are expected to show reduced performance on hybrids but empirical evidence suggests the opposite (cf. references in Table 1b).

As for plant invasions, new genotype assemblages created after recombination will increase the potential for rapid adaptive evolution. Also, fixed heterosis may increase fitness. 
webs (Pearson et al. 2000). In another study, Louda and Arnett (2000) observed that the number of a native tephritid fly feeding in flower heads of Platte thistle, Cirsium canescens, dropped precipitously as the attack rate by the oligophagous weevil Rhinocyllus conicus, a biological control agent released in North America against exotic thistles, increased. It was therefore argued that the addition of $R$. conicus to the food web associated with Platte thistle flower heads caused that decrease in the density of the native fly. Negative effects of biological control agents on native food webs are a critical issue in classical biological control since it is probably impossible to consider all potential indirect effects in pre-release studies. Hence, as in assessing the risk of direct nontarget effects of a biological control agent (see above), the introduction of classical biological control agents also entails some level of uncertainty in terms of evaluating potential indirect negative effects on native species or ecosystem processes.

Biological invasions as well as any attempts to control invasive species are processes that are embedded in an ecosystem context (Zavaleta et al. 2001). By occupying a large amount of space in invaded habitats and usually harboring impoverished invertebrate and microbial assemblages (cf. Introduction), invasive plants are expected to impose significant direct negative effects on the native vegetation with indirect negative effects (effects mediated through third species) on higher trophic levels and energy flow. Moreover, successful biological control is expected to alter native species composition and hence exhibit indirect nontarget effects, be it in a positive, e.g., through the recovery of plant species richness and the associated herbivore assemblages, or in a negative way, such as by competitive resource depletion or apparent competition.

\section{The future of classical biological control: bridging the gap between applied and fundamental research}

Where science meets application

\section{Studies towards success rating and ecosystem impact}

The actual success rate of classical biological weed control is a matter of debate and largely depends on the definition of success (McFadyen 1998; van Klinken and Raghu 2006). As outlined above, goals should be clearly defined at the beginning of biological control projects against which success can be evaluated. Identification of the goals of a biological control program will help not only agent prioritization, but also selection of those parameters that should be measured before and after the release of the agents in order to document the effect of the biological control agent and to assess whether the overall goal of the project has been achieved or not.

There is still a serious lack of data demonstrating the negative effects of invasive plants on native ecosystems (Braithwaite et al. 1989; Pysek and Pysek 1995; Holmes and Cowling 1997). The assessment of subsequent potential positive effects of successful classical biological control on biodiversity recovery or other ecosystem properties is thus impeded (McEvoy et al. 1993). Evidence is accumulating that invasive species can seriously impact ecosystem patterns or processes (Ehrenfeld 2003; Levine et al. 2003; d'Antonio and Hobbie 2005). In most cases, however, the state of the ecosystem prior to plant invasion is poorly documented. Comparing long-term experimental plots that have been recently invaded by weeds with noninvaded plots or monitoring species composition and ecosystem properties in areas where the first specimens of an invasive plant have just established may provide valuable information on the actual impact of invasive species on ecosystem properties. When weed invasions occur in already heavily disturbed habitats, the goal of a management scheme is not to restore the species composition or ecosystem processes to the level prior to invasion, but to restore the biodiversity and ecosystem properties that are characteristic for the affected area (Hulme 2006). One way to estimate ecosystem recovery after successful biological control is to carry out weed removal experiments. Removing the invasive plant Impatiens glandulifera from riparian habitats resulted in an increase in plant species richness, but a significant number of species recolonizing such sites were other exotic species (Hulme and Bremner 2006). Comparing invaded with noninvaded sites provides a less powerful assessment of the relationship between an invasive plant and ecosystem properties, but can still provide useful information in cases where invasive plants cannot be removed without major habitat disturbance. Unravelling the 
nature of the relationship between weed density and its impact on biodiversity or ecosystem processes will affect the level of control desired, and will hence help in selecting the appropriate management scheme (Thomas and Reid 2007). Clearly, a more ecosystembased approach could help to better assess and quantify the direct and indirect negative effects of the invasive weed as well as the indirect positive and negative effects of successful biological control.

\section{Towards an improved pre-release impact assessment}

A critical and presently still rather neglected issue with regard to improving biological control success is a better understanding of the mechanisms leading to high densities of the control agent (Gassmann 1996). With regard to predicting agent impact on weed density, great progress has been achieved by considering the plant's population dynamics as this can provide valuable information on the Achilles heel of the plant's lifecycle (Raghu et al. 2006). This information can then be used in selecting biological control agents (or other management schemes) that reduce the transition probability of that specific stage (cf. above on: Selection of effective biological control agents). Whether the biological control agent will be able to reduce the critical transition in a weed's lifecycle by the required amount depends on the combination of the per capita impact, which itself is a function of the type, timing, and degree of damage, and the population dynamics of the biological control agent. The per capita impact of a herbivore on a plant can be relatively easily tested and current regulations for biological control often ask for some basic information on the potential impact on the target weed. However, there is little evidence that the per capita impact of a biological control agent is correlated with success in biological control programs. The prerequisite of successful biological control is that the biological control agent reaches high population densities in the introduced range (Gassmann 1996). Hence, predicting the likelihood of success of a biological control programme largely depends on improving our understanding of the effects of biotic (e.g., host-plant attributes, mortality due to parasitism or predation) and abiotic factors (climate) on the survival, development rate and fecundity of biological control agents (Gassmann
1996; Zalucki and van Kinken 2006). To date, only a few attempts have been made to model the population dynamics of biological control agents (e.g., Buckley et al. 2005; Zalucki and van Kinken 2006).

A further critical issue to better predict agent impact is to study and include the various mechanisms of tolerance and compensation to herbivory, both at the level of individual plants and at the level of the population. Plant responses to herbivore damage vary enormously. The net effect of a single or repeated defoliation event on the cumulative growth of plants can be zero, negative or positive, depending on the availability of leaf area, meristems, stored nutrients, soil resources, and the frequency, timing, and intensity of defoliation (e.g., Hawkes and Sullivan 2001). Mechanisms leading to plant tolerance include a large variety of physiological processes ranging from increased light intensity for surviving leaf area, increased photosynthetic rate per leaf area, improved water and nutrient availability to surviving leaf tissue and delayed senescence up to mobilization of stored resources and the activation of dormant buds (Crawley 1997). Despite considerable knowledge available on tolerance in plant-herbivore systems (see, e.g., Strauss and Agrawal 1999, and references therein), little work has been undertaken to explore the effects of plant tolerance on the population dynamics of plant-herbivore systems. Recently, for the first time and as part of a weed biocontrol project, Buckley et al. (2005) explored the dynamic effects of different herbivore damage functions to quantify the effect of plant tolerance to herbivory on the population dynamics of a plant-herbivore system. The damage function assumes that plants can compensate for low levels of herbivory, which introduces a time lag into the system when herbivore numbers are low. At the population level, plants are often well buffered against catastrophic events, such as seed loss caused by biological control agents. Compensatory changes operate in a density-dependent manner, e.g., through density-dependent seedling mortality and density-dependent fecundity, with the net result that a wide range of starting densities is reduced to a narrow range of final population size. As with tolerance operating at the individual plant level, determination of thresholds is crucial for realistic predictions and effective management. There may therefore be a jump from no effect to considerable effect as that threshold is passed, possibly leading to more unstable 
dynamics rather than a smooth continuous decline in plant densities with increasing seed loss (Buckley et al. 2005). Recent advances that combine specific and well-thought-out experiments with comparative field studies and sophisticated modeling tools are most encouraging and have a great potential to increase our predictive power for the outcome of plant-herbivore dynamics underlying biological control programmes against plant invaders.

\section{Studies towards integrative biological control}

Weed problems in intensively managed as well as natural and seminatural ecosystems arise from a multitude of factors often involving changes in the disturbance level (Alpert et al. 2000) and are thus rarely caused by a single weed species. Biological control, with its inherently narrow spectrum, has to be considered as an integrated component of a welldesigned pest management strategy, not as a cure by itself. In most cases, combinations of biological agents with other weed management tools will be needed to produce acceptable levels of overall weed control. Such integration can be viewed as a vertical integration of various control tactics against a single weed species or as a horizontal integration across different weed species in an ecosystem (see MüllerSchärer 2002, for a short review and examples of integration). Comparative, experimental, and modeling studies on possible synergistic or antagonistic effects of biocontrol in combination with existing or potential management options and with land use are therefore greatly needed (Huwer et al. 2002; Buckley et al. 2004; Paynter 2005).

\section{Where application meets science}

Biological invasions have been recognized as unprecedented bio-geographical experiments to study both ecological and evolutionary processes (Callaway and Maron 2006). This certainly holds also for classical biological control. Bio-geographic comparisons of the mechanisms underlying the two epidemic events of plant invasion and population increase of the biological control agent offer important insight into biotic and abiotic factors regulating the abundance and distribution of plants and their associated herbivorous species. The interrelationship between the invasive plant, the invaded ecosystem, and the biological control agent can be used to test key hypotheses in ecology, such as the role of top-down versus bottom-up regulation of vegetation composition, or the likelihood and rate of ecosystem recovery in relation to the ecosystem property affected by plant invasions. Much has been learned in the past few decades about the effect of specialist herbivores on plant population dynamics from biological control programmes (Briese 2000; Myers and Bazely 2003; Sheppard et al. 2003; Briese 2004; Raghu et al. 2006). Recently, it is increasingly acknowledged that plant invasions and classical biological control programmes are also great models with which to study evolution (Lee 2002; Müller-Schärer et al. 2004; Bossdorf et al. 2005). It has been proposed that populations of an invasive plant are likely to undergo rapid directional selection more often in the introduced than in the native range because the number of links between introduced species and the surrounding community is low during the early stages of introduction (Thompson 1998). A few evolutionary hypotheses that could be tested using biological control programmes against plant invaders are listed in Table 2. If, for instance and as predicted by the EICA hypothesis, the invasive plant has evolved increased vigor at the expense of antispecialist defence, biological control agents are expected to increase their survival and fecundity, which in turn could facilitate fast herbivore population build-up and increase the impact on the target weed (Table 2b). Alternatively, it was suggested that effective tolerance mechanisms might be common in plant invaders (Müller-Schärer et al. 2004). If this is the case, this can help to explain why many introductions of insect biocontrol agents exhibit only weak negative effects on their host (McFadyen 1998; Myers and Bazely 2003). It might also explain the resulting superabundance of some of the biocontrol agents over extended time periods (Pearson and Callaway 2003, and see above on: Potential impact on native food webs) because tolerance, unlike resistance, is generally not expected to regulate the population dynamics of its consumers. In the context of plant invasion, tolerance has received little attention (Bossdorf et al. 2005). Clearly, more experimental work is needed to better understand how altered selection through changes in the intensity of competition and herbivory in the new range might influence the evolution of plant tolerance during the 
invasion process (van Kleunen and Schmid 2003; Bossdorf et al. 2004), as this is expected to influence the outcome of biological control interventions (Müller-Schärer et al. 2004, Table 2c). Further, as discussed above, both intra- and interspecific hybridization were found to be an important process in several examples of plant invasions, but little is yet know about how this might affect plant traits relevant for interactions with higher trophic organisms including biological control agents (Table 2d).

While it is often impossible to exactly trace back the plant genotypes that have been originally introduced into a new range, this information can be collected from biological control agents and subsequently used to investigate evolutionary processes. For example, by independently manipulating the number of individuals and the genetic variation of the different releases of a biological control agent, one can test the relative importance of these two factors on establishment success, subsequent population growth, and rate of evolution (Table 2e). In this context, it is important that only individuals from populations of a biological control agent that have been shown to have an acceptable host range are released, as populations may vary in their degree of host specificity (Sheppard et al. 2005).

We hope to have shown with these few examples of testable hypotheses that biological control programmes against plant invaders indeed offer a great opportunity to gain new insights into basic processes in ecology and evolution as well as to create a stronger link between these two still quite independent disciplines of biology. This in turn will also benefit biological control by making it safer and more efficient.

Acknowledgements We greatly thank Thomas Steinger for the many stimulating discussions, Andy Sheppard, Rieks van Klinken, Mark van Kleunen, Markus Fischer, and three anonymous reviewers for their critical and constructive comments on an earlier draft of this manuscript, and Wade Jenner for improving the English text. The work was supported by the Swiss National Science Foundation (SNSF; grant number 3100-065356 to HMS) and the National Centre of Competence in Research (NCCR) Plant Survival, research programme of the SNSF.

\section{References}

Agrawal AA (2000) Host-range evolution: adaptation and trade-offs in fitness of mites on alternative hosts. Ecology 81:500-508
Alpert P, Bone E, Holzapfel C (2000) Invasiveness, invasibility and the role of environmental stress in the spread of nonnative plants. Perspect Plant Ecol Evol Syst 3:52-66

Amsellem L, Noyer JL, Le Bourgeois T, Hossaert-McKey M (2000) Comparison of genetic diversity of the invasive weed Rubus alceifolius Poir. (Rosaceae) in its native range and in areas of introduction, using amplified fragment length polymorphism (AFLP) markers. Mol Ecol 9:443-455

Ayres DR, Strong DR (2001) Origin and genetic diversity of Spartina anglica (Poaceae) using nuclear DNA markers. Am J Bot 88:1863-1867

Barrett SCH, Husband BC (1990) The genetics of plant migration and colonization. In: Brown AHD, Clegg MT, Kahler AL, Weir BS (eds) Plant population genetics. Breeding, and Genetic Resources, Sinauer, pp 254-277

Bernays EA (2000) Neural limitations in phytophagous insects: implications for diet breadth and evolution of host affiliation. Annu Rev Entomol 46:703-727

Blossey B (1995) Host specificity screening of insect biological weed control agent as part of an environmental risk assessment. In: Hokkanen HMT, Lynch JM (eds) Biological control: benefits and risks. Cambridge University Press, Cambridge, pp 53-63

Blossey B, Nötzold R (1995) Evolution of increased competitive ability in invasive nonindigenous plants: a hypothesis. J Ecol 83:887-889

Bossdorf O, Schröder S, Prati D, Auge H (2004) Palatability and tolerance to simulated herbivory in native and introduced populations of Alliaria petiolata (Brassicaceae). Am J Bot: 856-862

Bossdorf O, Auge H, Lafuma L, Rogers WE, Siemann E, Prati D (2005) Phenotypic and genetic differentiation between native and introduced plant populations. Oecologia 144:1-11

Braithwaite RW, Lonsdale WM, Estbergs JA (1989) Alien vegetation and native biota in tropical Australia: the impact of Mimosa pigra. Biol Conserv 48:189-210

Briese DT (1996) Phylogeny: can it help us to understand hostchoice by biological control agents? In: Moran VC, Hoffman JH (eds) Proceedings of the IX international symposium on biological control of weeds. University of Cape Town, Cape Town, pp 63-70

Briese DT (2000) Classical biological control. In: Sindel BM (ed) Australian weed management systems. RG \& FJ Richardson, Melbourne, pp 161-192

Briese DT (2003) The centrifugal phylogenetic method used to select plants for host-specificity testing of weed biological control agents: can and should it be modernised? In: Jacob HS, Briese DT (eds) Improving the selection, testing and evaluation of weed biological control agents. CRC Technical Series, Australian Weed Management, Adelaide, pp 23-33

Briese DT (2004) Weed biological control: applying science to solve seemingly intractable problems. Aust J Entomol 43:304-317

Briese DT (2005) Translating host-specificity test results into the real world: the need to harmonize the yin and yang of current testing procedures. Biol Control 35:208-214

Buckley YM, Rees M, Paynter Q, Lonsdale WM (2004) Modelling integrated weed management of an invasive shrub in tropical Australia. J Appl Ecol 41:547-560 
Buckley YM, Rees M, Sheppard AW, Smyth MJ (2005) Stable coexistence of an invasive plant and biocontrol agent: a parameterized coupled plant-herbivore model. J Appl Ecol 42:70-79

Burdon JJ, Marshall DR (1981) Biological control and the reproductive mode of weeds. J Appl Ecol 18:649-658

Callaway RM, Maron JL (2006) What have exotic plant invasions taught us over the past 20 years? Trends Ecol Evol 21:369-374

Cappuccino N, Carpenter D (2005) Invasive exotic plants suffer less herbivory than non-invasive exotic plants. Biol Lett 1:435-438

Chaboudez P, Sheppard AW (1995) Are particular weeds more amenable to biological control? A reanalysis of mode of reproduction and life history. In: Delfosse ES, Scott RR (eds) VIII International symposium on biological control of weeds. DSIR/CSIRO, Melbourne, Lincoln University, Canterbury, pp 95-102

Cory JS, Myers JH (2000) Direct and indirect ecological effects of biological control. Trends Ecol Evol 15:137-139

Courtney SP, Chen GK, Gardner A (1989) A general model for individual host selection. Oikos 55:55-65

Crawley MJ (1989) Insect herbivores and plant population dynamics. Annu Rev Entomol 34:531-564

Crawley MJ (1997) Plant ecology. Blackwell, Oxford, 717 pp

d'Antonio CM, Hobbie SE (2005) Plant species effects on ecosystem processes. In: Sax DF, Stachowicz JJ, Gaines SD (eds) Species invasions: insights into ecology, evolution and biogeography. Sinauer Associates, Sunderland, pp 65-84

DeLoach CJ (1995) Progress and problems in introductory biological control of native weeds in the United States In: Delfosse ES and Scott RR (eds) Proceedings of the 8th international symposium on biological control of weeds. CSIRO Publishing, pp 111-112

Dennill GB, Donnelly D (1991) Biological control of Acacia longifolia and related weed species (Fabaceae) in South Africa. Agric Ecosyst Environ 37:115-135

Ehrenfeld JG (2003) Effects of exotic plant invasions on soil nutrient cycling processes. Ecosystems 6:503-523

Ehrlich PR, Raven PH (1964) Butterflies and plants: a study in coevolution. Evolution 18:586-608

Ellstrand NC, Schierenbeck KA (2000) Hybridization as a stimulus for the evolution of invasiveness in plants? Proc Natl Acad Sci USA 97:7043-7050

Elton CS (1958) The ecology of invasions by animals and plants. Methuen, London

Falconer DS, Mackay TFC (1996) Introduction to quantitative genetics. Longman, Harlow

Finckh MR, Wolfe MS (1997) The use of biodiversity to restrict plant disease and some consequences for farmers and society. In: Jackson LE (ed) Ecology in agriculture. Academic, New York, pp 203-237

Fritz RS, Moulia C, Newcombe G (1999) Resistance of hybrid plants and animals to herbivores, pathogens, and parasites. Annu Rev Ecol Syst 30:565-591

Fry JD (1990) Trade-offs in fitness on different hosts: evidence from a selection experiment with a phytophagous mite. Am Nat 136:569-580

Futuyma DJ (2000) Potential evolution of host range in herbivorous insects. In: van Driesche R, Heard TA, McClay
AS and Reardon R (eds) Host-specificity testing of exotic arthropod biological control agents - the biological basis for improvement in safety. USDA Forestry Service Publication FHTET-99-1, pp 42-53

Garrett KA, Mundt CC (1999) Epidemiology in mixed host populations. Phytopathology 89:984-990

Gaskin JF, Schaal BA (2002) Hybrid Tamarix widespread in U.S. invasion and undetected in native Asian range. Proc Natl Acad Sci USA 99:11256-11259

Gassmann A (1996) Classical biological control of weeds with insects: a case for emphasizing agent demography. In: Moran VC, Hoffmann JH (eds) Proceedings of the IX international symposium on biological control of weeds. University of Cape Town, Cape Town, pp 19-26

Goeden RD (1983) Critique and revision of Harris' scoring system for selection of insect agents in biological control of weeds. Prot Ecol 5:287-301

Goolsby J, Palmer B, van Klinken RD (2006) Maximizing the contribution of native-range studies towards the identification and prioritization of weed biocontrol agents. Aust $\mathrm{J}$ Entomol 45:276-285

Grace BS, Müller-Schärer H (2002) Biological control of Senecio vulgaris in carrots (Daucus carota) with the rust fungus Puccinia Lagenophorae. Basic Appl Ecol 4: 375-384

Handley RJ, Steinger T, Treies UA, Müller-Schärer H (2008) Testing the evolution if increased competitive ability (EICA) hypothesis in a novel framework. Ecology 89:407-417

Harris P (1973) The selection of effective agents for the biological control of weeds. Can Entomol 105:1495-1503

Harris P (1985) Biological control of weeds: bureaucrats, botanists, beekeepers, and other bottlenecks. In: Delfosse ES (ed) Proc. VI int. symp biol. contr. weeds. agric. Can, Vancouver, Canada, pp 3-12

Harris P, Zwölfer H (1968) Screening of phytophagous insects for biological control of weeds. Can Entomol 100: 295-303

Hawkes CV, Sullivan JJ (2001) The impact of herbivory on plants in different resource conditions: a meta-analysis. Ecology 82:2045-2058

Hoffmann JH, Impson FAC, Moran VC, Donnelly D (2002) Biological control of invasive golden wattle trees (Acacia pycnantha) by a gall wasp, Trichilogaster sp. (Hymenoptera: Pteromalidae), in South Africa. Biol Control 25:64-73

Holmes PM, Cowling RM (1997) The effects of invasion by Acacia saligna on the guild structure and regeneration capabilities of South African fynbos shrublands. J Appl Ecol 34:317-332

Hulme PE (2006) Beyond control: wider implications for the management of biological invasions. J Appl Ecol 43: 835-847

Hulme PE, Bremner ET (2006) Assessing the impact of Impatiens glandulifera on riparian habitats: partitioning diversity components following species removal. J Appl Ecol 43:43-50

Huwer RK, Neave MJ, Dowling PM, Lonsdale WM, Sheppard AW, Briese DT, Michalk DL (2002) Integrated weed management (IWM) in perennial pasture and grazing management, herbicide strategies and biological control. 
In: Spafford Jacob H, Dodd J, Moore JH (eds) Proceedings of the 13th Australian weeds conference. Plant Protection Society of WA, Perth, pp 727-730

Impson FAC, Moran VC, Hoffmann JH (2004) Biological control of an alien tree, Acacia cyclops, in South Africa: impact and dispersal of a seed-feeding weevil, Melanterius servulus. Biol Control 29:375-381

Kalischuk AR, Bourchier RS, McClay AS (2004) Post hoc assessment of an operational biocontrol program: efficacy of the flea beetle Aphthona lacertosa Rosenhauer (Chrysomelidae: Coleoptera), an introduced biocontrol agent for leafy spurge. Biol Control 29:418-426

Karowe DN (1990) Predicting host range evolution: colonization of Coronilla varia by Colias philodice (Lep., Pieridae). Evolution 44:1637-1647

Keane RM, Crawley MJ (2002) Exotic plant invasions and the enemy release hypothesis. Trends Ecol Evol 17:164-170

Lee CE (2002) Evolutionary genetics of invasive species. Trends Ecol Evol 17:386-391

Levine JM, Vila M, d'Antonio CM, Dukes JS, Grigulis K, Lavorel S (2003) Mechanisms underlying the impacts of exotic plant invasions. Proc R Soc Lond B 270:775-781

Louda SM, Arnett AE (2000) Predicting non-target ecological effects of biological control agents: evidence from Rhinocyllus conicus. In: Spencer NR (ed) Proceedings of the $\mathrm{X}$ international symposium on the biological control of weeds. Agricultural Research Service, Department of Agriculture, Bozeman, pp 551-567

Louda SM, Pemberton RW, Johnson MT, Follett PA (2003) Nontarget effects-the achilles heel of biological control? Retrospective analyses to reduce risk associated with biocontrol introductions. Annu Rev Entomol 48: 365-396

Maron JL, Gardner SN (2000) Consumer pressure, seed versus safe-site limitation, and plant population dynamics. Oecologia 124:260-269

McClay AS, Balciunas JK (2005) The role of pre-release efficacy assessment in selecting classical biological control agents for weeds-applying the Anna Karenina principle. Biol Control 35:197-207

McEvoy PB, Rudd NT, Cox CS, Huso M (1993) Disturbance, competition, and herbivory effects on ragwort Senecio jacobaea populations. Ecol Monogr 63:55-57

McFadyen REC (1998) Biological control of weeds. Annu Rev Entomol 43:369-393

Mitchell CE, Power AG (2003) Release of invasive plants from fungal and viral pathogens. Nature 421:625-627

Müller H (1988) An experimental and phytocentric approach for selecting effective biological control agents: insects on spotted and diffuse knapweed, Centaurea maculosa and C. diffusa (Compositae). In: Delfosse ES (ed) VII International symposium of biological control of weeds. Ist. Sper. Patol. Veg. (MAF), Rome, pp 181-190

Müller H (1991) The impact of root herbivory as a function of plant density and competition: survival, growth and fecundity of Centaurea maculosa (Compositae) in field plots. J Appl Ecol 28:759-776

Müller-Schärer H (2002) Principles of integrated pest management with emphasis on weeds. In: Pimentel D (ed) Encyclopedia of pest management. Marcel Dekker, New York, pp 1-5
Müller-Schärer H, Frantzen J (1996) An emerging system management approach for biological weed control in crops: Senecio vulgaris as a research model. Weed Res 36:483-491

Müller-Schärer H, Rieger S (1998) Epidemic spread of the rust fungus Puccinia lagenophorae and its impact on the competitive ability of Senecio vulgaris in celeriac during early development. Biocontrol Sci Technol 8:59-72

Müller-Schärer H, Steinger T (2004) Predicting evolutionary change in invasive, exotic plants and its consequences for plant-herbivore interactions. In: Ehler LE, Sforza R, Mateille T (eds) Genetics, evolution and biological control. CAB International, Wallingford, pp 137-162

Müller-Schärer H, Scheepens PC, Greaves MP (2000) Biological control of weeds in European crops: recent achievements and future work. Weed Res 40:83-98

Müller-Schärer H, Schaffner U, Steinger T (2004) Evolution in invasive plants: implications for biological control. Trends Ecol Evol 19:417-422

Myers JH (1985) How many insect species are necessary for successful biocontrol of weeds? In: Delfosse ES (ed) Proceedings of the VI international symposium on biological control of weeds. Agriculture Canada, Vancouver, pp 77-82

Myers JH, Bazely DR (2003) Ecology and control of introduced plants. Cambridge University Press

Neuffer B, Hurka H (1999) Colonization history and introduction dynamics of Capsella bursa-pastoris (Brassicaceae) in North America: isozymes and quantitative traits. Mol Ecol 8:1667-1681

Novak SJ, Mack RN (1993) Genetic variation in Bromus tectorum (Poaceae)-comparison between native and introduced populations. Heredity 71:167-176

Page AR, Lacey KL (2006) Economic impact assessment of Australian weed biological control. CRC Weed Management, Technical Series No 10, p 164

Paynter Q (2005) Evaluating the impact of a biological control agent Carmenta mimosa on the woody wetland weed Mimosa pigra in Australia. J Appl Ecol 42:1054-1062

Pearson DE, Callaway RM (2003) Indirect effects of hostspecific biological control agents. Trends Ecol Evol 18:456-461

Pearson DE, McKelvey KS, Ruggiero LF (2000) Non-target effects of an introduced biological control agent on deer mouse ecology. Oecologia 122:121-128

Pelser PB, Gravendeel B, van der Meijden R (2002) Tackling speciose genera: species composition and phylogenetic position of Senecio sect. jacobaea (Asteraceae) based on plastid and nrDNA sequences. Am J Bot 89:929-939

Pemberton RW (2000) Predictable risk to native plants in weed biological control. Oecologia 125:489-494

Pysek P, Pysek A (1995) Invasion by Heracleum mantegazzianum in different habitats in the Czech Republic. J Veg Sci 6:711-718

Raghu S, Wilson JR, Dhileepan K (2006) Refining the process of agent selection through understanding plant demography and plant response to herbivory. Aust J Entomol 45:308-316

Reed DH, Frankham R (2001) How closely correlated are molecular and quantitative measures of genetic variation? A meta-analysis. Evolution 55:1095-1103 
Roitberg BD (2000) Threats, flies and protocol gaps: can evolutionary ecology safe biological control? In: Hochberg ME, Ives AR (eds) Parasitoid population biology. Princeton University Press, Princeton, pp 254-265

Schaffner U (2001) Host-range testing in biological control of weeds: what can it tell us, and how can it be better interpreted? Bioscience 51:1-9

Schierenbeck KA, Hamrick JL, Mack RN (1995) Comparison of allozyme variability in a native and an introduced species of Lonicera. Heredity 75:1-9

Sheppard AW (2003) Prioritising agents based on predicted efficacy: beyond the lottery approach. In: Spafford HJ, Briese DT (eds) Improving the selection, testing and evaluation of weed biological control agents. Cooperative Research Centre for Australian Weed Management, Adelaide, pp 11-21

Sheppard AW, Cullen JM, Aeschlimann J-P (1994) Predispersal seed predation on Carduus nutans (Asteraceae) in southern Europe. Acta Oecol 15:529-541

Sheppard AW, Hill R, DeClerck-Floate RA, McClay A, Olckers T, Quimby PC Jr, Zimmermann HG (2003) A global review of risk-benefit-cost analysis for the introduction of classical biological control agents against weeds: a crisis in the making? Biocontrol News Info 24:91-108

Sheppard AW, van Klinken RD, Heard TA (2005) Scientic advances in the analysis of direct risks of weed biological control agents to nontarget plants. Biol Control 35: $215-226$

Silvertown JW, Charlesworth D (2001) Introduction to plant population ecology. Blackwell Scientific Publications, Oxford, $347 \mathrm{pp}$

Simberloff D, Stiling P (1996) How risky is biological control. Ecology 77:1965-1974

Strauss SY, Agrawal AA (1999) The ecology and evolution of plant tolerance to herbivory. Trends Ecol Evol 14: 179-185

Thomas MB, Reid AM (2007) Are exotic natural enemies an effective way of controlling invasive plants? Trends Ecol Evol 22:447-453

Thompson JN (1998) Rapid evolution as an ecological process. Trends Ecol Evol 13:329-332

Turanli F, Schaffner U (2004) Oviposition specificity of the specialist Tinthia myrmosaeformis under different degree of behavioural restrictions. Biol Control 30:274-280 van Kleunen M, Schmid B (2003) No evidence for an evolutionary increased competitive ability (EICA) in the invasive plant Solidago canadensis. Ecology 84: 2816-2823

van Klinken RD (2000) Host specificity testing: why do we do it and how we can do it better. In: Van Driesche RG, Heard TA, McClay AS and Reardon R (eds) Proceedings of the $\mathrm{X}$ international symposium on biological control of weeds. USDA Forest Service Bulletin, FHTET-99-1, Morgantown, West Virginia, USA, Bozeman, Montana. USDA, pp 54-68

van Klinken RD, Edwards OR (2002) Is host-specificity of weed biological control agents likely to evolve rapidly following establishment? Ecol Lett 5:590-596

van Klinken RD, Raghu S (2006) A scientific approach to agent selection. Aust J Entomol 45:253-258

Walker NF, Hulme PE, Hoelzel AR (2003) Population genetics of an invasive species, Heracleum mantegazzianum: implications for the role of life history, demographics and independent introductions. Mol Ecol 12:1747-1756

Wapshere AJ (1974) A strategy for evaluating the safety of organisms for biological weed control. Ann Appl Biol 77:201-211

Withers TM, Barton Brown L (1998) Possible causes of apparently indiscriminant oviposition in host specificity tests using phytophagous insects. In: Zalucki MP, Drew RAI, White GG (eds) Proceedings of the 6th Australasian applied entomological research conference, Brisbane, Australia, 29 September-2 October 1998, pp 565-571

Withers TM, Barton Brown L, Stanley J (1999) Host specificity testing in Australasia: towards improved assays for biological control. Scientific, Indooroopilly

Wolfe LM (2002) Why alien invaders succeed: support for the escape-from-enemy hypothesis. Am Nat 160:705-711

Zalucki MP, van Kinken RD (2006) Predicting population dynamics of weed biological control agents: science or gazing into crystal balls? Aust J Entomol 45:331-344

Zavaleta ES, Hobbs RJ, Mooney HA (2001) Viewing invasive species removal in a whole-ecosystem context. Trends Ecol Evol 16:454-459

Zhu Y, Chen H, Fan J, Wang Y, Li Y, Chen J, Fan J, Yang S, $\mathrm{Hu}$ L, Leung H, Mew TW, Teng PS, Wang Z, Mundt CC (2000) Genetic diversity and disease control in rice. Nature 406:718-722 